\title{
2. Individual liberty in public health - no trumping value
}

Kalle Grill, Ph.D., Research Fellow, Department of Philosophy, Uppsala University.kalle.grill@filosofi.uu.se

\subsection{Introduction}

Public health policy often limits people's liberty for their own good. The very point of many types of public health measures is to restrict people's options in order to stop them from doing unhealthy things, for example use harmful recreational drugs or drive without a seatbelt. While such restrictive public health policies enjoy widespread support, so does the traditional liberal idea that liberty (or autonomy) is a higher value, to be given priority in most, if not all, circumstances. In this text, I will defend the thesis that liberty is an important value, but with no claim to priority.

Public health ethics is very much concerned with finding the appropriate approach to liberty. There is some consensus that the main goal of public health is to promote other values than liberty, typically population health (Holland 2007, p. 10-11). Some authors argue that this rather consequentialist goal must be controlled by a strong commitment to individual liberty, so that interference with liberty is justified only under certain conditions, if at all (I will provide some examples below). Other authors find this traditional liberal perspective ill fitted for the evaluation of public health policy, with its essentially non-individualist aims. This latter position may lead to attempts to develop a more community-oriented interpretation of central liberal values (Jennings 2009), or to a more radical rejection of the privileged status of liberty (Dawson 2009). To this debate, I will contribute three arguments against treating liberty as a trumping value, preceded by an argument to the effect that even moderate liberal positions are committed to treating liberty as a trump in many cases. Two of the arguments against 
trumping resemble arguments presented elsewhere (Grill 2010), but are here set in the context of public health more specifically.

Public health policy crucially targets populations or groups. This means that individual liberty typically cannot be protected through respectful personal interactions the way it can in clinical settings. Prohibitions and requirements are blunt tools. The population perspective also raises important and difficult questions concerning how to balance one person's liberty against another person's health, as well as some people's liberty interest in having a rich variety of options against other people's liberty interests in structuring their lives by making their environment safer and more conducive to health. I have discussed these questions elsewhere (Grill 2009) and will here disregard interpersonal balancing problems in order to focus on the simple case where all are equally affected by a policy - having their liberty limited but some other value, typically their health, promoted or protected.

My arguments are directed at the liberal who shares my conviction that liberty is valuable, whether or not this value is reducible to some higher value in the final analysis. I will therefore take the value of liberty for granted. I will assume, furthermore, that any government must take a stand on public health issues, either by making policy or by abstaining, and then this decision must be justified in terms of how it affects relevant values. In other words, I will not discuss the legitimacy of government authority in general.

\subsection{Trumping}

When two values are in conflict in the sense that both of them cannot be fully realized, a straightforward approach is to balance these conflicting values according to their relative importance or weight. Such a balancing approach may be consequentialist in a broad sense, incorporating such liberal values as respect for individual choice. However, a balancing approach may also be based on prima facie duties and so be an instance of deontology. For the sake of simplicity, I will speak no more of duties, but only of values, with the understanding that value can refer either to consequentialist outcomes, or to the fulfilment of prima facie duties. 
Trumping occurs when, instead of balancing, one value automatically overrides one or more other values, with no consideration of the extent to which each is affected. From the perspective of balancing, trumping appears to amount to the attribution of indefinitely greater importance to some values, or to the lexical ordering of some values before others. However, friends of trumping typically do not think in terms of indefinite importance or lexical priority, but rather have a more loose idea of what makes one value trump others.

When it comes to limitation of liberty, the most explicit account of trumping is arguable that of Joel Feinberg (1986):

"The most promising strategy for the anti-paternalist is to construct a convincing conception of personal autonomy that can explain how that notion is a moral trump card, not to be merely balanced with considerations of harm diminution in cases of conflict, but always and necessarily taking moral precedence over those considerations" (1986, p. 26).

Anti-paternalism is the doctrine that paternalism is morally wrong or unacceptable. On most accounts of paternalism, a policy can be paternalistic even it does no good, as long as the motivation or rationale for the policy is to do good. Such policies are of course pointless. If we restrict our attention, therefore, to public health policies that do in fact promote population health, the connection between anti-paternalism and trumping is very close. That such paternalism is wrong means that the value of unrestricted liberty always defeats the value of promotion or protection of population health. To take this position quite generally, without consideration of the details of any particular case, is in all essence to hold that the value of liberty trumps the value of population health.

True to his own recommendation, Feinberg attempts to construct an account of personal autonomy as a moral trump, in large part by appealing to the readers intuitive response to imagining being forced to do things and be in ways that others deem best, with no consideration of one's own will. Such intuitions are powerful, and may explain why so many authors, albeit realising that some instances of paternalism must be acceptable, presume that paternalism is normally unacceptable, even if it promotes or protects people's health and other fundamental interests.

In the general philosophical literature on paternalism, it is common to accept anti-paternalism as a rule, while arguing that paternalism is ac- 
ceptable in some cases. The proposed conditions for justified paternalism include that the aim be preservation of autonomy (Dworkin 1972; Kleinig 1984), that the benefits be much larger than the costs (Groarke 2002), and that the person would consent to limitation under certain hypothetical circumstances (Van De Veer 1986). Explicitly or implicitly, these accounts entail that when the appropriate condition is not met, then paternalism is unjustified. It is unjustified in these remaining cases not because the value of liberty is weighed against the value of health and other interests a person may have and found greater in all cases. These authors make no such comparisons. Unless special conditions are met, paternalism is unjustified, it seems, because liberty simply trumps other values for a person, such as the value of health.

In the literature on liberty-limiting public health policy specifically, it has become common practice to list a number of conditions for when paternalism is justified, with the assumption that it is unjustified in all other cases. In a much cited article (Childress et al., 2002), ten authorities on medical ethics state that public health measures must meet five "justificationary conditions" which "determine whether promoting public health warrants overriding such values as individual liberty". The conditions are effectiveness, proportionality, necessity, least infringement, and public justification. A policy that does not meet these conditions, for example because another policy would have been less intrusive (though perhaps more likely to be effective) is supposedly not justified. The policy may still have great positive effects on public health, and the infringement may be small. It seems highly unlikely, therefore, that the value of liberty is greater than the value of health in all cases not covered by the conditions. In those cases, therefore, liberty must simply trump population health. ${ }^{1}$ Even authors who are in favour of far-reaching and invasive measures to protect population health tend to believe that there must be more to the justification of such measures than mere balancing (e.g. Bayer and Fairchild 2004, pointing to the need for "a set of principles that would preserve a commitment to the realm of free choice").

\footnotetext{
${ }^{1}$ Childress has reaffirmed his position in a more recent co-authored article (Childress \& Bernheim 2008). Other influential lists of conditions for justified limitation of liberty in public health include Kass 2001 and Upshur 2002.
} 
While few authors are as uncompromising as Feinberg, the most common positions on liberty in public health are clearly anti-paternalist, though with exceptions. In other words, these positions treat liberty as a trumping value in many but not all cases. Trumping, however, has several undesirable consequences. If there are exceptions to the trumping, these consequences do not follow from the exceptions. They do, however, follow from those cases that are not exceptions. In this and the following three sections, I will briefly describe three undesirable consequences of trumping. In brief, the first problem is that the friend of trumping must either accept a narrow conception of liberty, which disregards many instances of apparent liberty limitation, or accept clearly counter-intuitive results in some cases. The second problem is that trumping leads to peculiar jumps in justifiability when comparing very similar policies. The third is an unwarranted disregard for the liberty of less able decision-makers.

\subsection{First problem with trumping - wrong answers or narrow liberty}

Some public health policies apparently have great positive consequences and lead to rather trivial limitations of liberty. The prohibition of heroin might be a real world example. Assume for arguments sake that this prohibition is enforced not by harsh punishment of users and small-scale dealers, but by effective prevention of production and importation. Assume also that there are plenty of other hallucinogenic drugs available (such as cannabis and perhaps LSD), which are weaker, and thus less addictive. In these circumstances, the prohibition of heroin might have very positive effects, preventing people from becoming addicted to heroin, and hence losing interest in their lives, mismanaging their jobs and neglecting their children. In such circumstances, furthermore, an effective prohibition would not seriously limit anyone's liberty. Still, liberty is limited, and if liberty is a trump in this case, the prohibition is unjustified.

Now add the assumption that the people who would start to use heroin were it available are not reckless teenagers or people in desperate circumstances, but adult people with comfortable lives who would simply be attracted by the fast route to ecstasy. Notice also that the policy targets first use; it is not a policy directed at people who are slaves under their 
addiction. This all means that the policy cannot be defended by claiming it protects people who are incapable to direct their lives. If the prohibition of heroin seems exceedingly illiberal even in this hypothetical example, consider the case of a hypothetical drug that is more addictive than heroin, has less pleasant effects and is much more hazardous, but which is in strong demand due to some quirk of popular culture (cf. Arneson 2005, pp. 272-3, for similar examples).

There are plenty of other examples of very reasonable public health policies, including seat belt laws, water fluoridation, and product safety regulation banning everything from exploding TVs to poisonous food (even when clearly indicated on the packaging). Strict anti-paternalists would seem to be opposed to these kinds of public health policies (unless, perhaps, they are implemented for the sake of a willing majority aiming to restrict their own options, or if the harms to non-consenting others are substantial). Moderate anti-paternalists, who believe in trumping with exceptions, will be opposed to these kinds of public health policies unless they met certain conditions. The policies may very well not meet such conditions (if for example some less restrictive policy would be possible).

Confronted with examples like these, the friend of trumping can of course bite the bullet and reject the policies as unjustified, but this is counter-intuitive and in some cases amounts to liberty fetishism (critics will construct ever more devastating hypothetical scenarios where very trivial limitations of liberty yield enormous benefits). In fact, friends of trumping that see this problem with their position tend not to bite the bullet, but rather argue that for any reasonable apparently liberty-limiting principle, liberty is not actually limited. Common explanations for this is that people do not really or truly want to make the unhealthy choices prevented by the policy (Dworkin 1972), that the policy has long term effects which yield a net increase in liberty (Sneddon 2001), or simply that the limitation in question is so trivial. These strategies, however, belittle liberty, or at least imply too narrow a conception of liberty.

That people of normal capacity are prevented from doing what they want to do is a limitation of their liberty, even if they would not want these things after an advanced course in nutrition or ten sessions of psychotherapy. Wants that are easily changed by improved information or insight may possibly warrant less respect than more sturdy wants, but they certainly warrant some respect as long as they remain. Similarly, that 
someone is restricted at present is a limitation of her liberty even if this restriction means that she will be more autonomous or have more options five years from now. And, lastly, even very trivial limitations, such as banning some types of candy or some rather obscure and dangerous sport, are nonetheless limitations.

The various "not really liberty" strategies have in common a focus on something more important or long term or both, a sort of liberty that is more worthwhile than the relatively trivial or temporary or superficial instances. This focus is admirable, but the mistake is to refuse to recognize the lower forms of liberty as liberty at all. This mistake becomes clearer when we aggregate a lot of such small liberties. It also becomes clearer when we realize that liberty may be only one among several values threatened by the same policy.

It may be tempting to claim, in the face of a trivial limitation of liberty with great benefits, that this limitation doesn't really limit liberty, or doesn't limit real liberty. For example, a ban on a certain new and hazardous recreational drug, enforced by policing and moderate punishments, may seem not to limit liberty in any interesting sense. Consider, however, a case where the banned drug is popular among the minority, and where a similar new drug, popular among the majority, and even more hazardous, is not banned. Assume that this asymmetry makes the policy unfair or discriminative. Assume also that although unfair, the policy is still beneficial for the minority and that this benefit just barely outweighs the unfairness so that the policy is justified, having considered only fairness and health effects. Now, if the policy would be in any way liberty-limiting, this would make the policy less justified and so tip the balance, making it all things considered unjustified. In such a case, one sees more clearly the price of a narrow conception of liberty - on such a conception the fact that the policy is restrictive or intrusive will not even weigh in on the matter.

In actual policy-making, that some people's liberty is limited and that this has some benefits for the same people are typically only two considerations among several. Our position on liberty-limiting policy should cover such common cases (if not all cases). Given this general ambition, liberty cannot be reduced to a core of the most important liberties, but must include both our most central life choices and our everyday, mundane choices. With this inclusive, wide understanding of liberty, however, it is quite unreasonable to insist that liberty trumps other values. Quite to 
the contrary, liberty should sometimes be limited just because the benefits in terms of population health are greater than the liberty cost to that same population.

\subsection{Second problem with trumping - jumps in justifiability}

What does it mean more precisely that liberty trumps other values for a person or group? It might mean only that no limitation of the liberty of a certain group should be accepted whatever the benefit to that group. If so, however, we must ask how to evaluate cases where a limitation of liberty can produce both benefits to the group, for example in the form of improved health, and other desirable consequences, such as increased fairness, or benefits to third parties. For example, banning some dangerous motor sport may both protect people who would otherwise practice that sport from harm, and protect the local and global environment (to the benefit of other people). Assume that the environmental benefit of banning the sport is just about outweighed by the liberty cost, making the ban unjustified considering only environmental and liberty effects. Now, the suggested definition of trumping does not preclude the direct harm prevention from counting in favour of the policy, making it all things considered justified. However, this seems contrary to the intentions of the friends of trumping. It also seems peculiar, or even slightly incoherent, to hold that liberty trumps harm prevention when these are the only two concerns, but can be outweighed by harm prevention as soon as there is some relevant third concern. We should, therefore, take trumping to mean that benefits to people, which are caused by limiting their liberty, can never even contribute to the justification of such liberty-limitation.

This understanding of trumping, reasonable as it is compared to the alternatives, leads to peculiar jumps in justifiability. This is partly because factors determining whether or not some behaviour is an expression of liberty come in degrees. For example, our liberty is limited only if the limitation targets a choice or an action that is to some extent voluntary. Preventing people from giving up their money under gun threat, or from sleepwalking into empty elevator shafts, is not to limit their liberty (unless, perhaps, they have declined intervention in an earlier, more volun- 
tary state). How much and what kind of voluntariness is required for an intervention to amount to a limitation of liberty is a central issue for antipaternalism, and Feinberg consequently dealt extensively with voluntariness. Voluntariness minimally involves being informed and being able to process information into decisions. Such ability and informedness come in degrees - tiny bits of information and tiny improvements in decisionmaking ability make decisions more voluntary. There must be some point where there is sufficient voluntariness for trumping to set in.

The benefits of public health policy may be great. They may, like seat belt laws, save thousands of lives annually in a medium size state. Since I have disregarded interpersonal balancing problems at the outset, assume that all drivers are equally informed and able when it comes to the decision whether or not to use a seatbelt. Assume further that, as in the actual history of most countries, most people will not use seatbelts unless required by law to do so. Now consider the public health policy of making seat belts mandatory. Does this policy limit people's liberty? Different opinions have been offered, some of them involving one of the "not really liberty" strategies criticised above. Our concern now is not whether liberty is limited, however. Our concern is this consequence of trumping: If people are so badly informed and so incompetent as decision-makers when it comes to seatbelt use that forcing them to wear belts does not limit their liberty, then the great health benefits are a very strong consideration in favour of this policy. If, on the other hand, people are somewhat more informed and able, so that forcing them to wear seat belts does limit their liberty, then the great health benefits are trumped and so do not contribute to the justification of the policy. As a result, at the threshold between insufficient and sufficient voluntariness, the justifiability of the policy takes a "jump".

If, as in the case of seat belt laws, the health benefits are great, then the jump in justifiability is very long. One policy can be overwhelmingly justified, while a very similar policy can be overwhelmingly unjustified. This is unreasonable. The problem here is not the standard problem of arbitrary line drawing. It is uncontroversial that some policies are justified and some are not, and that very small differences may make the difference between this moral status of policy. We must distinguish between the binary status of being either justified or unjustified, and the quality of being more or less justified in the sense of being supported by a larger or 
smaller excess of pro reasons over con reasons. This latter quality has practical impact for example in that more justified policies should take priority over less justified ones. Now the problem with trumping is that it entails that very minor empirical differences potentially give rise to huge gaps in justifiability. This is both conceptually peculiar and practically difficult. It is conceptually peculiar because it is very hard to accept that very minor differences can change the moral status of a policy from overwhelmingly justified to overwhelmingly unjustified. It is practically difficult because it is hard to conduct sound public policy if priorities change dramatically with very small developments in for example public risk awareness. $^{2}$

\subsection{Third problem with trumping - no liberty for the less able}

There are not only, as noted above, small liberties for informed and able decision-makers; there are also liberties, small and large, for less informed and less able decision-makers. I propose that liberty is important not only for the most able, but also for minors, for the ignorant, and for people who are confused, intoxicated or affected by strong emotions (these being factors which are generally considered to decrease voluntariness). It is not as if the value of having some control over one's own life kicks in only at a certain degree of voluntariness. Perhaps there is some level under which people cannot choose for themselves or cannot appreciate selfdetermination. Liberty, however, has value for people that are well above this level but that we should nonetheless obviously coerce in their own interest, for example 15-year olds. With this, every liberal should agree. However, this presents the friend of trumping with a hard choice.

\footnotetext{
${ }^{2}$ It may be suggested that there is no sharp line but rather a grey area. If this area is grey only in the sense that it is hard to know when a policy amounts to limitation of liberty, this does not affect the argument, which is focused on the peculiarity of there being a jump, regardless of our ability to pinpoint it. If the area is grey in the sense that it is genuinely indeterminate whether some levels of voluntariness are sufficient, then there is no sudden jump but rather a twilight zone of indeterminacy. Jumps are avoided at the price of giving up comprehensiveness. This is no improvement.
} 
Three positions are possible for the friend of trumping: First, she can insist that the liberty of young teens is of another type than the liberty of (allegedly) informed and rational adults and so does not activate the trumping quality of liberty. This distinction, however, is mysterious. One might say that the important value is not liberty but autonomy, and that young teens are not fully autonomous. This does not help, however, as there is no difference in kind between almost full autonomy and full autonomy, whatever full autonomy is exactly. Full autonomy is presumably partly determined by decision-making ability, which comes in degrees.

Second, the friend of trumping can claim that the liberty of young teens does trump other concerns. However, we have seen the problems such a view entails even for very able decision-makers. Even those who bite the bullet and reject as unjustified seemingly reasonable public health policies targeting adults cannot reasonably accept such passivity in relation to young teens.

Third, the friend of trumping can say that for young teens, the value of liberty is appropriately reflected in its relative importance, with no need for trumping. For example, the liberty cost of increasing the minimum moped driving age from 15 to 16 in some state may be too great relative to the small expected decrease in road accidents. This third position is the most plausible. But if this is one's position on young teens, it is entirely unclear why things should be any different for competent adults. Interference with more able decision-makers generally yields smaller rewards, since there is less room for improvement. It may also be that interference with more able decision-makers has a greater cost in terms of liberty, because more liberty (or autonomy) is sacrificed in some sense. However, none of this indicates that the benefits of liberty-limiting policy cannot contribute to the justification of policy, or that these benefits may not outweigh the costs.

It may be suggested that the above argument disregards the important distinction between the competent and the incompetent, or between the healthy and the (mentally) ill, or between adults and children. These categories, however, depend on underlying physical properties, which vary by degree. Once bestowed, legal status may admittedly make a normative difference. It is perhaps worse to limit the liberty of an adult, because this frustrates legitimate expectations induced by the legal system. However, such legal circumstances can only reinforce an underlying normative real- 
ity, which must be spelled out in terms of non-legal, concrete physical or psychological properties of persons. It would be hopelessly vacuous to argue that the people we must protect from intrusions are those that have been granted a legal right to be so protected. On the contrary, when deciding the proper age of majority and the conditions for legal competence, an important factor is the extent to which it is justified to limit people's liberty for their own good.

In conclusion, a trumping approach fails to address the issue of whether or not to interfere with less than sufficiently voluntary choices made by rather autonomous people such as young teens. It makes no sense that the liberty of people who barely reach the threshold of sufficient voluntariness should trump other concerns, while the liberty of people who make somewhat less voluntary choices is simply one value among others.

\section{Conclusion}

While there are many positions on the justification of liberty-limiting public health policy, most positions share a commitment to the idea that liberty trumps other concerns in all or some cases. Such trumping has very undesirable consequences: It forces us to choose between a very narrow conception of liberty and morally very counter-intuitive conclusions, it leads to peculiar jumps in justifiability, and it leaves out less able decisionmakers, such as young teens. We should therefore reject trumping in favour of a balancing approach, according to which liberty is one value among many and decisions to limit liberty can and must be justified by showing how such limitation will yield benefits that outweigh the disvalue of the loss of liberty.

A balancing approach avoids the objections to trumping. Furthermore, reasoning in terms of the balancing of various values has strong methodological and democratic advantages. An official statement that a policy is justified because it does not conflict with a trumping principle (with or without exceptions) says nothing about how policy-makers weigh different values. The public may possibly infer that policy-makers will abide by the principle in the future as well, but we will know nothing about how policy-makers will treat matters not covered by the principle. In contrast, relative value estimates are more transparent. A judgment that some public health measure leads to more good than bad is straightforward and can 
be fruitfully questioned and discussed. Public health officials can explain what exactly they expect to gain (so many saved lives, so many prevented illnesses) and what they are prepared to pay (so many people being detained, so many jobs not being done etc.), and why they find the gains more important than the losses.

\section{References}

Arneson, Richard. 2005. "Joel Feinberg and the Justification of Hard Paternalism". Legal Theory 11: 259-284.

Bayer, Ronald and Fairchild, Amy. 2004. "The Genesis of Public Health Ethics". Bioethics 18(6): 473-492.

Childress, J. F. et al. 2002. "Public health ethics: mapping the terrain," The Journal of Law, Medicine \& Ethics 30(2): 170-178.

Childress, J. F. and Bernheim, R. Gaare. 2008. "Public health ethics - Public justification and public trust" Bundesgesundheitsblatt-GesundheitsforschungGesundheitsschutz 51(2): 158-163.

Dawson, Angus. 2009. "Resetting the parameters: public health as the foundation for public health ethics", in: A. Dawson (ed) Public Health Ethics: Key Concepts and Issues in Policy and Practice. Cambridge: Cambridge University Press.

Dworkin, Gerald. 1972. "Paternalism". The Monist 56: 64-84.

Feinberg, Joel. 1986. Harm to Self. Oxford: Oxford University Press.

Grill, Kalle. 2009. "Liberalism, Altruism and Group Consent". Public Health Ethics 2(2): 146-157.

Grill, Kalle. 2010. "Anti-paternalism and Invalidation of Reasons”. Public Reason 2(2). 3-20.

Groarke, Louis. 2002. "Paternalism and Egregious Harm”. Public Affairs Quarterly 16: 203-230.

Holland, Stephen. 2007. Public Health Ethics. Cambridge: Polity Press.

Jennings, Bruce. 2009. "Public Health and Liberty: Beyond the Millian Paradigm". Public Health Ethics 2(2): 123-134.

Kass, Nancy E. 2001. “An Ethics Framework for Public Health". American Journal of Public Health 91(11): 1776-82.

Sneddon, Andrew. 2001. "What's Wrong With Selling Yourself Into Slavery? Paternalism and Deep Autonomy". Crítica 33(98): 97-121.

Upshur, R.E.G. 2002. "Principles for the Justification of Public Health Intervention". Canadian Journal of Public Health 93(2): 101-103.

Van de Veer, Donald. 1986. Paternalistic Intervention Princeton: Princeton University Press. 